\title{
The neuropathological films in the collection of the Museo Nazionale del Cinema in Turin
}

The Turinese pathologist Camillo Negro (Biella, I86I - Torino, I927) was one of the pioneers who experimented with the new means of cinema for scientific purposes. Between 1906 and I908, Negro filmed some 'exemplary cases' of patients under his custody at the Hospital for the Piccola Casa della Divina Provvidenza of Turin (Cottolengo) and the Section of Nervous Diseases at the Policlinico Generale (General Policlinic) in Turin. He did so with the help of Giuseppe Roasenda and in collaboration with Roberto Omegna, one of the most experienced cinematographers in Italy and destined to play an essential part in the national scientific film as well. Historically identified with the title LA NEUROPATOLOGIA (The neuropathology), these recordings were conceived with didactic goals but were also shown to audiences in occasion of scientific conferences. During the First World War Camillo Negro dedicated himself to the study of war syndromes and continued his cinematic documentation by filming some of the soldiers hurt at the front and recovering at the Military Hospital in Turin.

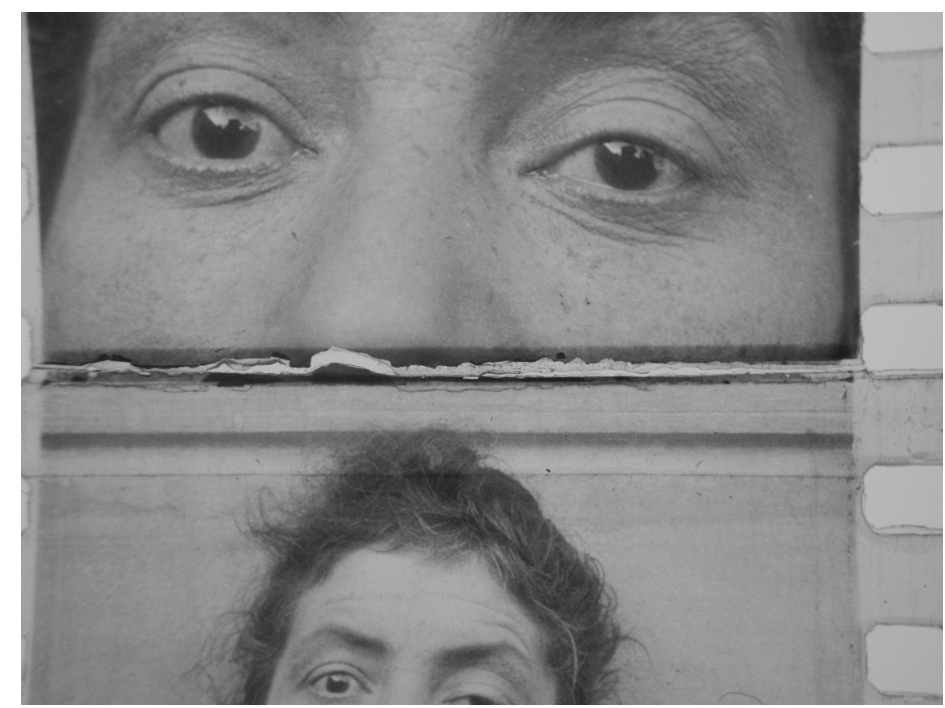

III. 1 Picture from Negro's LA NEUROPATOLOGIA

Source: Museo Nazionale del Cinema, Turin 


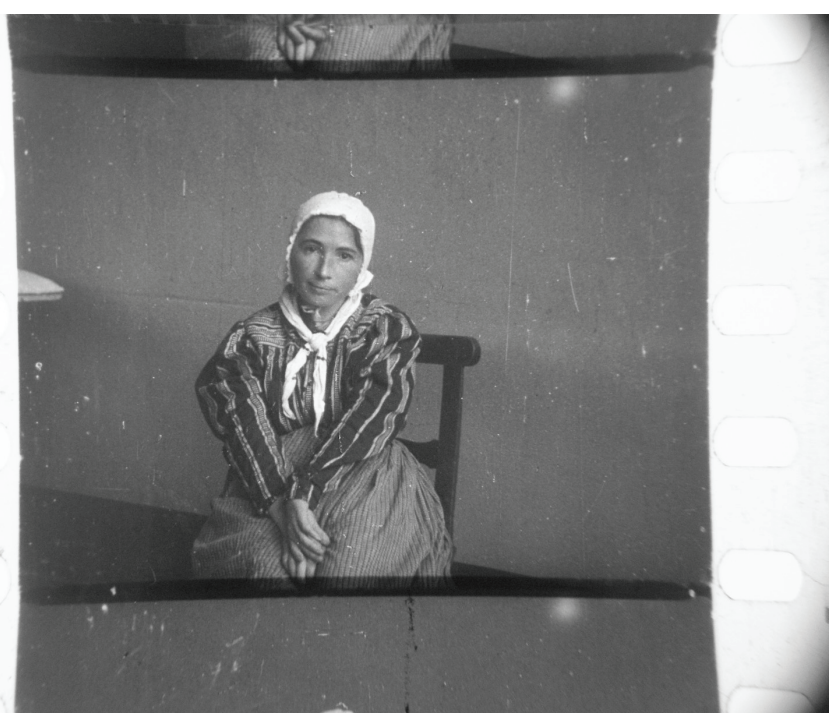

III. 2 Picture from Negro's LA NEUROPATOLOGIA

In I962 the Museo Nazionale del Cinema of Turin acquired a positive nitrate print of a part of the neuropathological films shot by Negro, to which later materials on $35 \mathrm{~mm}$ and $16 \mathrm{~mm}$ were added in I990. The fascination and the interest in these images did not go unnoticed, as LA NEUROPATOLOGIA was object of two restoration projects in 1993 (in a reduced version) and in I997. These prints led to a greater awareness of the work by Negro, by imposing particularly striking sequences to the scholarly imagination, such as the one in which a masked woman is caught in an attack of hysteria. A profound analysis of the nitrate print and the discovery of new materials preserved within the collection of the Museum, however, made it necessary to return to the work on the films by Negro. So in 20II, after long research, the Museum undertook a new edition $(35 \mathrm{~mm}$, safety polyester, positive, black and white and in colour, using the Desmet colouring method, I.000 m., ca. 48' at I 8 fps, a job realized at the L'Immagine Ritrovata film lab in Bologna), in collaboration with the Department of Neurosciences of the University of Turin.

In respect to the previous editions, the main alterations were three:

The materials shot in the first decade of the century were split from those dedicated to the war syndromes. This made the devastating impact of the Great War evident, within the clinical context of the neuropathological studies. Fundamental proved to be the paper documents kept at the Fondo Privato Omegna, the information provided by historian Bujor T. Rîpeanu, and the confrontation with films preserved at the Arhiva Nationala de Filme (National Film Archive) in Bucarest. The reintegration of the yellow tinting to the war materials contributed to indicate another difference with the earlier images in black and white, now in the first chapters of the anthology.

The order of the episodes shot between I906 and I908 was modified in respect to the previous editions, taking into consideration the fact that the sequences in the nitrate print were inedited. Serving as the basis for this reconstruction were various articles in contemporary magazines, in particular the detailed report published on I2 March 1908 in Phono Cinéma Revue about a projection held at the Salpêtrière in Paris. The new editing order - which, however, 
should be regarded as a working hypothesis - responds to a diagnostic path that proceeds from the small eye twitching caused by nystagmus to the big hysterical attack, in a progression from the particular to the general. It thus meets a logic that is both medical and visual.

Some I7 minutes of inedited materials were added that were found in the collection of the Museum. One reel of positive nitrate of 60 metres shows Negro and Roasenda in the company of an unmasked woman on the set of the famous hysterical scene. Unfortunately, the print had already gravely decomposed, so only few seconds of images could be saved, from which one doesn't understand whether this regards another hysterical attack, or a test after which one decided to mask the patient in order to protect her privacy. In addition to some inedited sequences of pathological gaits, another reel of positive nitrate presents Negro demonstrating a patient affected by tremors, while surrounded by his own collaborators. Moreover, thanks to fragments of camera negative and short sequences in 16 and $35 \mathrm{~mm}$ safety film, it has been possible to reconstruct the images of Negro investigating the injured foot of a soldier. Among the finds, nevertheless, the most significant sequence was the one showing a young man reliving the shellshock from the trenches on a matrass thrown on the ground in a room of the Military Hospital.

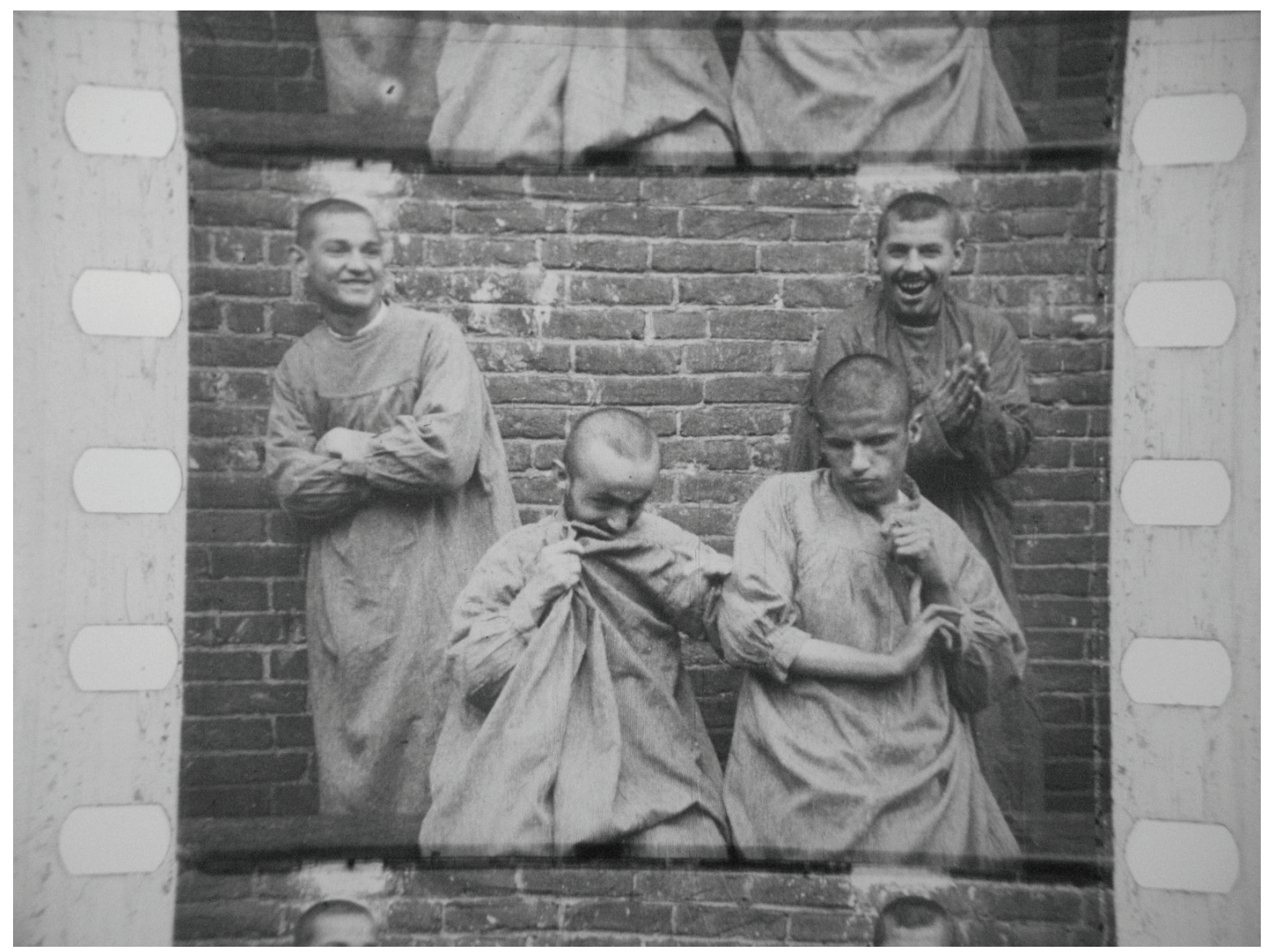

III. 3 Picture from Negro's La NeURopatolocia

Within the collection of the Museo Nazionale del Cinema also two films by Camillo's son, Fedele Negro, have been preserved. These are two $16 \mathrm{~mm}$ prints, probably shot in the early I930s. The first is a compilation of shots without a definitive editing, and shows patients affected by 
malformations of the limbs. The second is definitely more structured and was intended to promote with Queen Elena the effects of the so-called 'Bulgarian cure', a treatment of Parkinson syndrome patients, in order to obtain support and finance from the Italian Royal Family for the research led by Fedele Negro.

On top of their medical interest as testimonies of the representations of - now rare or forgotten - syndromes, these neuropathological films are precious occasions to stimulate more general reflections on the doctor-patient relationship, on the evolution of the concept of cure and pathology, and on the impossibility of neutrality of the cinematic recording.

Museo Nazionale del Cinema, Turin

Cineteca 